\title{
FIELD OBSERVATIONS AND MODEL PREDICTIONS OF WAVE TRANSFORMATION ON A MACRO-TIDAL BEACH, KOREA
}

\begin{abstract}
Jeseon Yoo ${ }^{1}$, Sungwon Shin ${ }^{2}$, Ki-Cheon $\mathrm{Jun}^{1}$, and Jae-Seol Shim ${ }^{1}$
Macro-tidal beach processes are influenced by complicated interactions of tide actions, coastal waves and morphological changes. Tidal cycles may be a primary forcing responsible for specific characteristics of hydrodynamic and morphological processes complicated on the intertidal flat in space and time. Macro-tidal sandy beaches are frequently developed in the west coast of Korea, experiencing seasonal variations of inter-tidal processes caused by a monsoonal climate in the Yellow Sea. Large winter waves tend to excite active beach morphological processes, inducing beach erosion and seaward-directed sediment transports. This study is intended to investigate and characterize intertidal hydrodynamics including wave dynamics in a macro-tide environment in Korea, by using a numerical model named COBRAS. The measured water surface elevation data are divided into wave and tidal components, in order to be used as inputs of the model. Tidal components in terms of water level change are implemented in the model by adding constant currents at the offshore boundary. Comparisons of the measurements and the predictions show a good performance of the model for wave height transformation and wave set-up across the macro-tidal beach.
\end{abstract}

Keywords: Macro-tidal, field observation, numerical model, RANS, and wave transformation

\section{INTRODUCTION}

The nearshore wave processes have been generally studied with an emphasis on wave-dominant coastal environments, in which tide-induced water level changes are not considerable. In contrast, field studies on hydrodynamics of macro-tidal environments are less found. Macro-tidal environments expose the intertidal zone periodically to dry atmosphere with tidal ranges of more than $4 \mathrm{~m}$ in water depth.

Macro-tidal beach processes are influenced by complicated interactions of tide actions, coastal waves and morphological changes. Tidal cycles may be a primary forcing responsible for specific characteristics of hydrodynamic and morphological processes complicated on the intertidal flat in space and time. For instance, a cyclic change of the intertidal beach from dry to wet conditions due to strong tidal flow actions further complicates hydrodynamic motions in shallow water under the wave propagations (Wright et al., 1982).

Macro-tidal sand beaches are frequently developed in the west coast of Korea, experiencing seasonal variations of inter-tidal processes caused by a monsoonal climate in the Yellow Sea. Typically, incident waves are likely to be small in summer, when tropical high atmospheric pressures are dominant around Korea. In contrast, large waves by stormy north western winds during winter months prevail along the west coast of Korea (Lee et al., 1999). Thus, the large winter waves tend to excite active beach morphological processes, inducing beach erosion seaward-directed sediment transports.

For those reasons, this study is intended to investigate and characterize intertidal hydrodynamics including wave dynamics in a macro-tide environment in Korea, by conducting a numerical simulation. Beach wave processes are one of important driving forces in coastal morphology by provoking beach erosions and sediment transports in inter-tidal shallow water areas, due to active wave breaking, energetic turbulence and violent near-bed velocities.

Herein, a numerical wave model, named COBRAS, was applied to simulate transformation of waves accompanied with tidal currents, because the field measurements of water surface elevations includes both waves and tides. In earlier studies, the COBRAS model (a RANS model, developed by Lin and Liu of Cornell University) has been used to investigate such beach processes with reasonable success, mostly, in coastal structures and wave-dominant natural beach. The model solves the RANS equations using VOF method and k-epsilon closure scheme. In many previous studies, COBRAS was used to simulate small-scale experiments instead of large-scale experiments or field observations due to the model stability. Torres-Freyermuth et al. (2007) tried to modify left boundary condition of COBRAS to improve the simulation of the field observation results. However, it is still approaching problems of RANS model at prototype time and spatial scales in terms of model robustness and stability. The field observation data are used to evaluate the capability of the RANS model to predict the cross-shore variations of free surface and velocities on the Mallipo Beach. The measured water

\footnotetext{
${ }^{1}$ Korea Institute of Ocean Science and Technology , Ansan, Gyeonggi-do, 427-744, South Korea

${ }^{2}$ Department of Energy plant, Kwandong University, Gangneung, Gangwon-do, 210-701, South Korea
} 
surface elevation data were divided into wave and tidal components, in order to be used as inputs of the model. In this study, comparisons of the measurements and the predictions show performance of the model for the wave transformation and wave run-up on the macro-tidal beach.

\section{FIELD DATA COLLECTION}

Intensive field experiments were carried out at a macro-tide environment, i.e. the Mallipo sand beach located in the west coast of Korea, during a transitional month from winter to spring in April, 2011. The Mallipo sand beach is extended by a wide inter-tidal flat in the cross-shore direction up to $400 \mathrm{~m}$. The beach has a tidal range of approximately $4 \sim 7 \mathrm{~m}$ and a nearly planar slope (s) of 0.026 on average (Fig. 1). Size distribution of sands sampled across the inter-tidal flat mainly ranges from 250 to $280 \mu \mathrm{m}$.
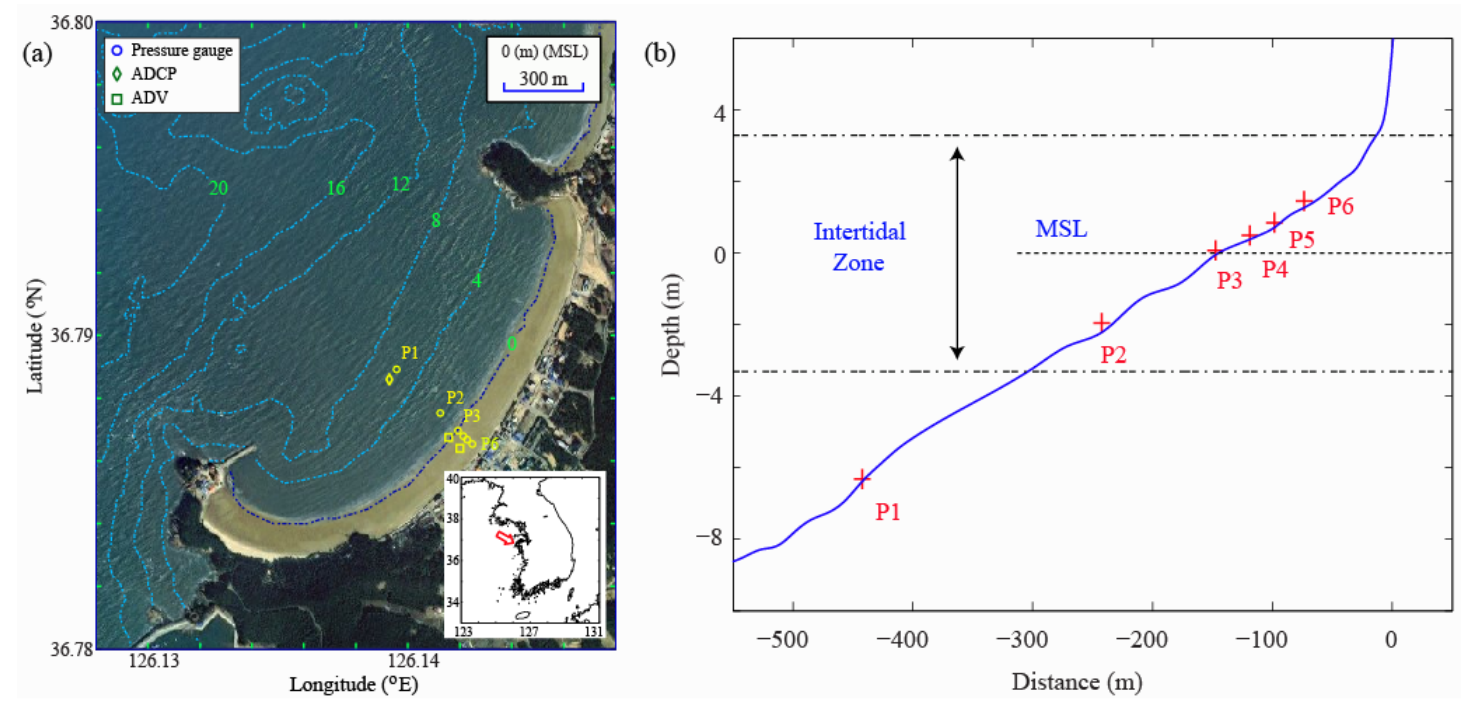

Figure 1. (a) Map of the Mallipo beach with depth contours and field instrumentations, (b) beach profile in the cross-shore direction.

The inter-tidal and sub-tidal field measurements were conducted during a period of 6 to 30 April, 2011. Hydrodynamic data were collected in a range of 1 to $9 \mathrm{~m}$ in depth (w.r.t. Approx. HWL) in the cross-shore direction using in situ sensors such as pressure sensor, ADV and ADCP. Locations and mean depths of instrumentations are indicated in Fig. 1. Geometric configurations of the inter-tidal and sub-tidal zone were surveyed using a differential global positioning system at low tide.

Wave height measurements along the cross-shore transect were analyzed to investigate variation of wave heights from the offshore to the inter-tidal zone. Here, incident wave heights at the offshore at 6$m$ depth were analyzed from water pressure data with correction of depth attenuation using linear wave theory. Changes of wave heights and water depths across the inter-tidal zone were also considered from the pressure data measured by the pressure gauges deployed on the seafloor. Fig. 2 shows a part of the field wave data collected during the measurement campaign. Since wave propagations across the intertidal zone were strongly affected by local water depths, the wave heights measured at the four intertidal locations were limited by depth changes in tidal cycle.

In order to simulate wave propagations under influence of tidal motions across the intertidal zone, three cases of tidal phase were selected herein, as shown in Fig. 2(a). 

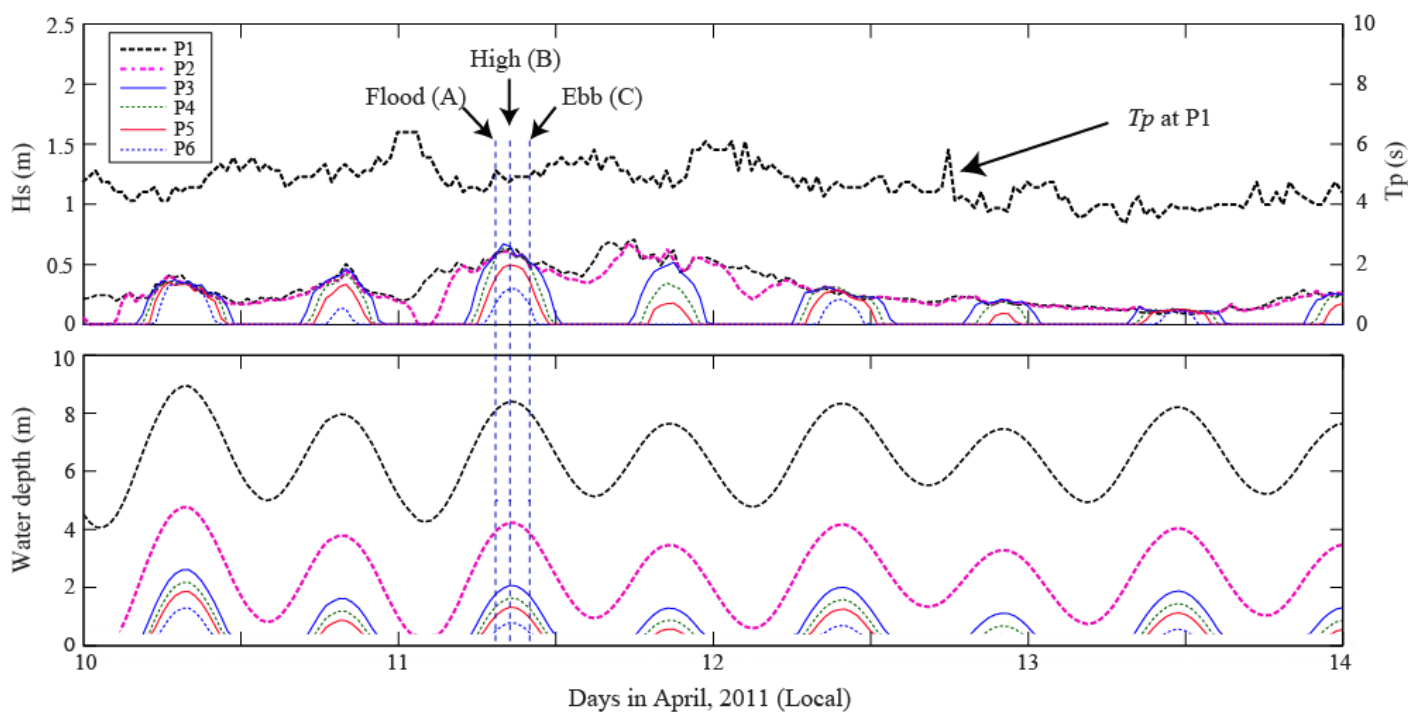

Figure 2. (a) Comparisons of wave heights measured by the offshore (P1) and inter-tidal (P2 P6) pressure sensors, (b) local water depths obtained from water pressure data of the sensors.

\section{NUMERICAL SIMULATION}

For COBRAS simulation, three different cases were selected considering flood tide and ebb tide as mentioned earlier. However, collected field observation data with weak tidal current have to be selected because the instrument locations when the strong tidal current exists were exposed to the air so that large portions of data were missed. Therefore, only two or three locations were available during that period.

Computational domain of COBRAS covered P1 through P6 as shown in Figure 3. Variable horizontal grid scales $(0.4 \sim 0.2 \mathrm{~m})$ were used to reduce the number of grid for computation expense. Vertical grid size was fixed to $0.1 \mathrm{~m}$.

Table 1 shows the input condition of three different cases for numerical simulations.
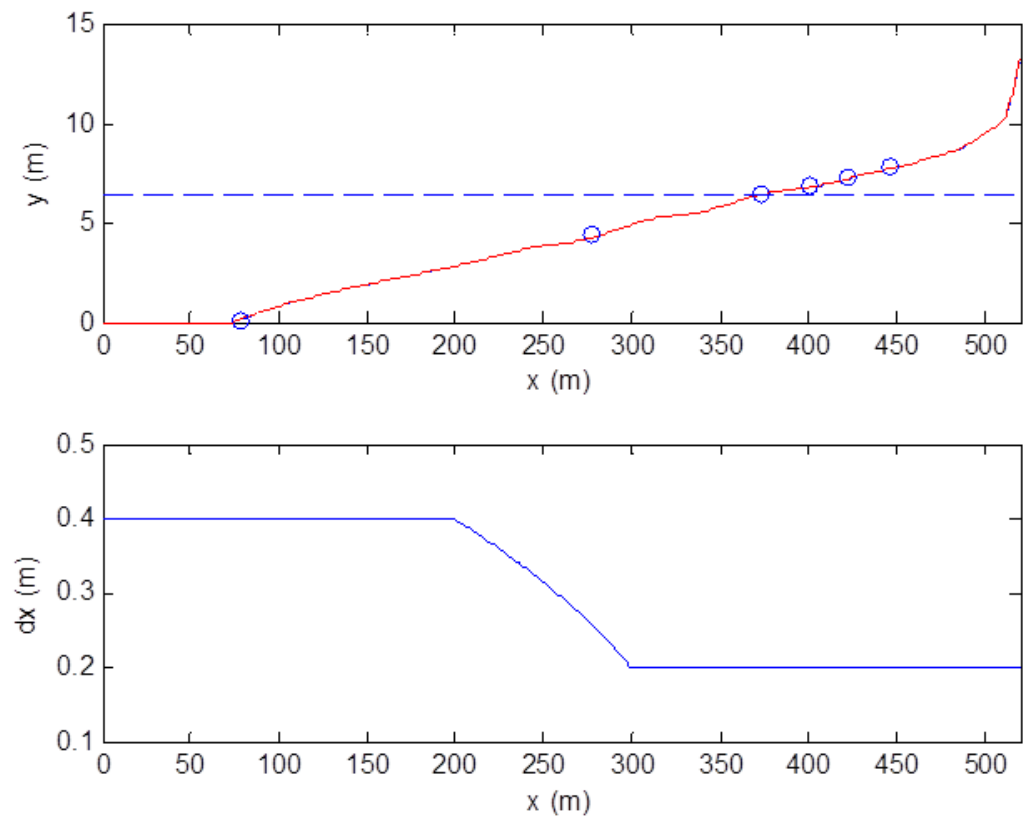

Figure 3 Computational domain of COBRAS (top) and horizontal grid size variation (bottom). 


\begin{tabular}{|c|c|c|}
\hline \multicolumn{3}{|c|}{ Table 1. Input wave and tide conditions for COBRAS simulations. } \\
\hline Case & Hydrodynamic conditions & Observation date and time \\
\hline 1 & Waves + high tide & 2011. 4. 11 8:30 AM \\
2 & Waves + ebb tide & $2011.4 .1111: 00 \mathrm{AM}$ \\
3 & Waves + flood tide & $2011.4 .117: 30 \mathrm{AM}$ \\
\hline
\end{tabular}

Irregular waves were generated based on the measured data at P1 by using source function as an internal wave generation method. In the mean time, uniform current was also generated from the left boundary based on the time averaged ADCP data from the field observation. Figure 4 shows an example snap shot of the COBRAS result. The figure indicates that most of waves are broken near the $40 \mathrm{~m}$ from the shoreline in this case. The contour and color bar are stand for turbulent kinetic energy. Generated water surface data at P1 (lower panel) look stable for a long period computation time.
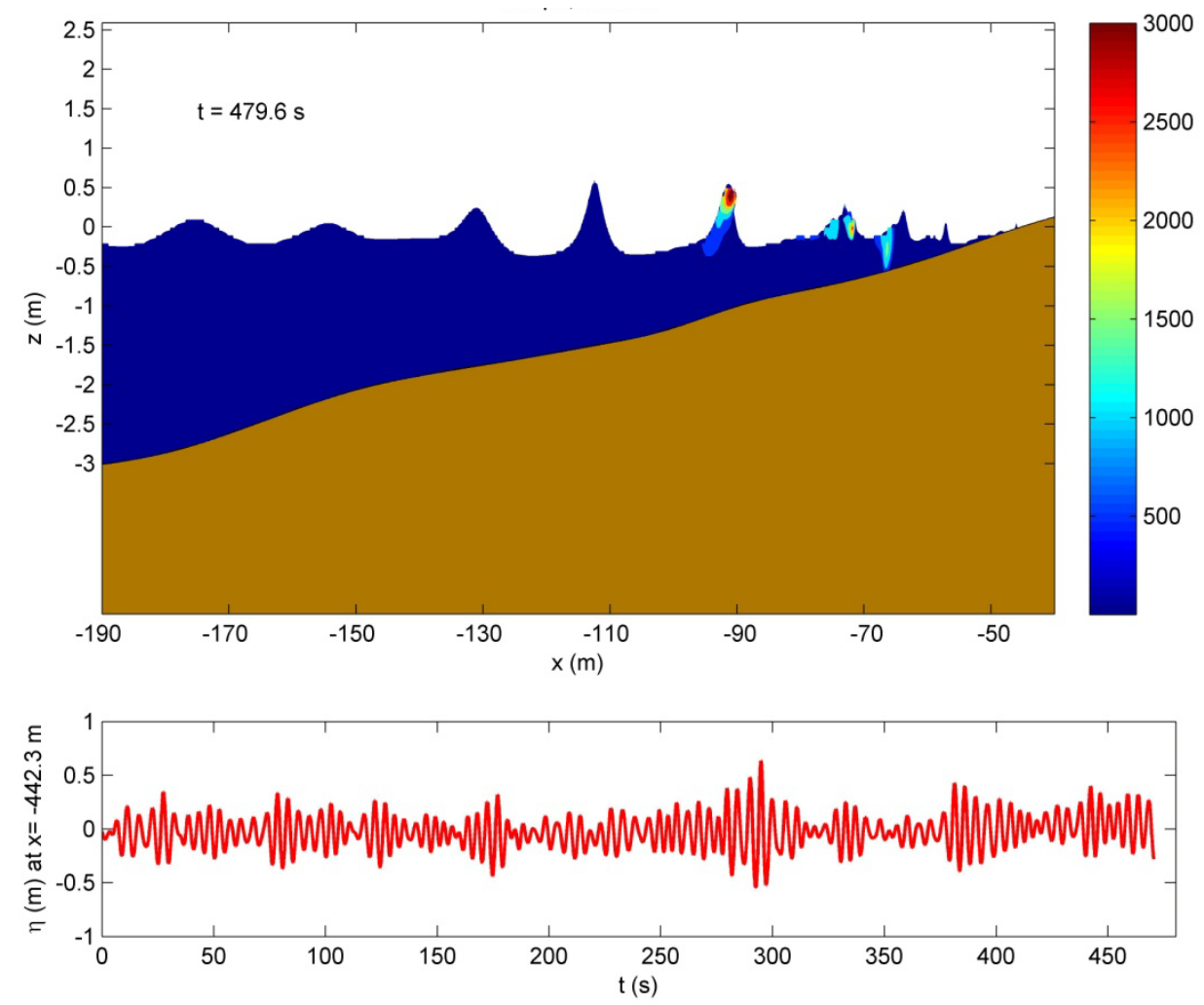

Figure 4 An example of COBRAS results. Upper panel shows the water surface elevation with the contour plot of turbulent kinetic energy. Lower panel shows the predicted water surface elevation at P1. The model predicted well about the water surface elevation compared with experimental data results.

Figure 5 to 7 are cross-shore wave height variations and setup for three cases. In all three cases, COBRAS predicted wave heights and setup qualitatively well compared with field data. However, in case 2 and 3, COBRAS slight overestimated wave height near the surf zone. The COBRAS data contains free surface elevation, horizontal and vertical fluid velocity, turbulent kinetic energy and pressure at each grid. However, because of the difficulty of field observation near the inter-tidal zone, available data for numerical model verification were not so many. Also because the selected cases include weaker tidal current it was so difficult to see the tidal current effect on wave transformation.

Therefore, COBRAS run two different cases again. One case was considered only wave component and the other case was considered same wave condition with $0.1 \mathrm{~m} / \mathrm{s}$ tidal current which can be seen in the west coast of Korea. Figure 8 shows the preliminary results of COBRAS for these two cases. Upper panel of the figure indicates the case considered only for waves. However, snap shot of the lower panel (wave + tidal current) looks different compared with upper panel even if both snap shot 
were taken at the same time step. This figure proves that wave breaking patterns are changed and runup ranges are larger when both waves and flood tide are combined.
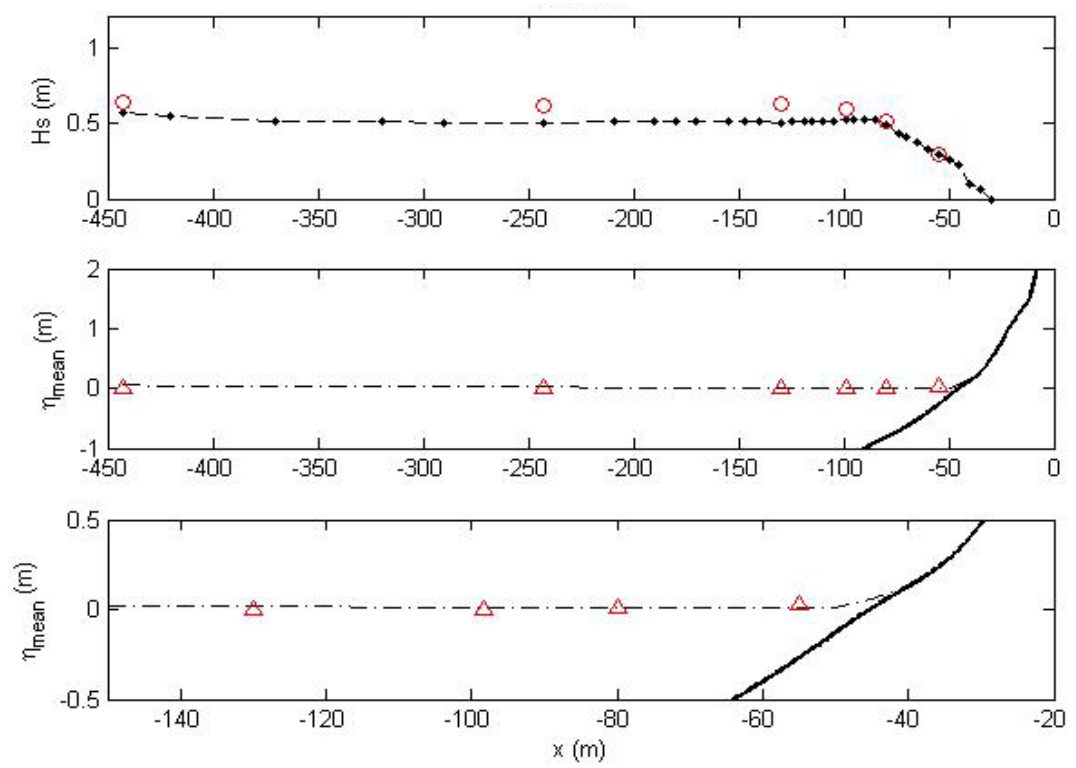

Figure 5 Cross-shore variations of wave heights (top) and setup (lower two panels) in Case 1.
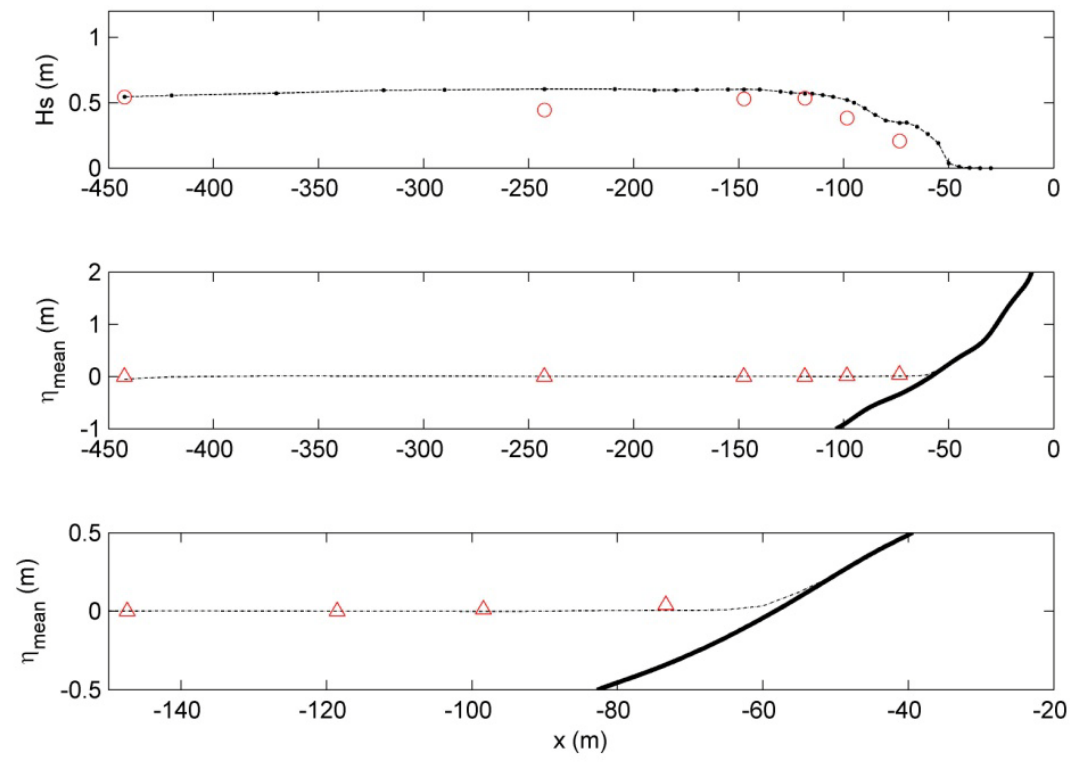

Figure 6 Cross-shore variations of wave heights (top) and setup (lower two panels) in Case 2. 

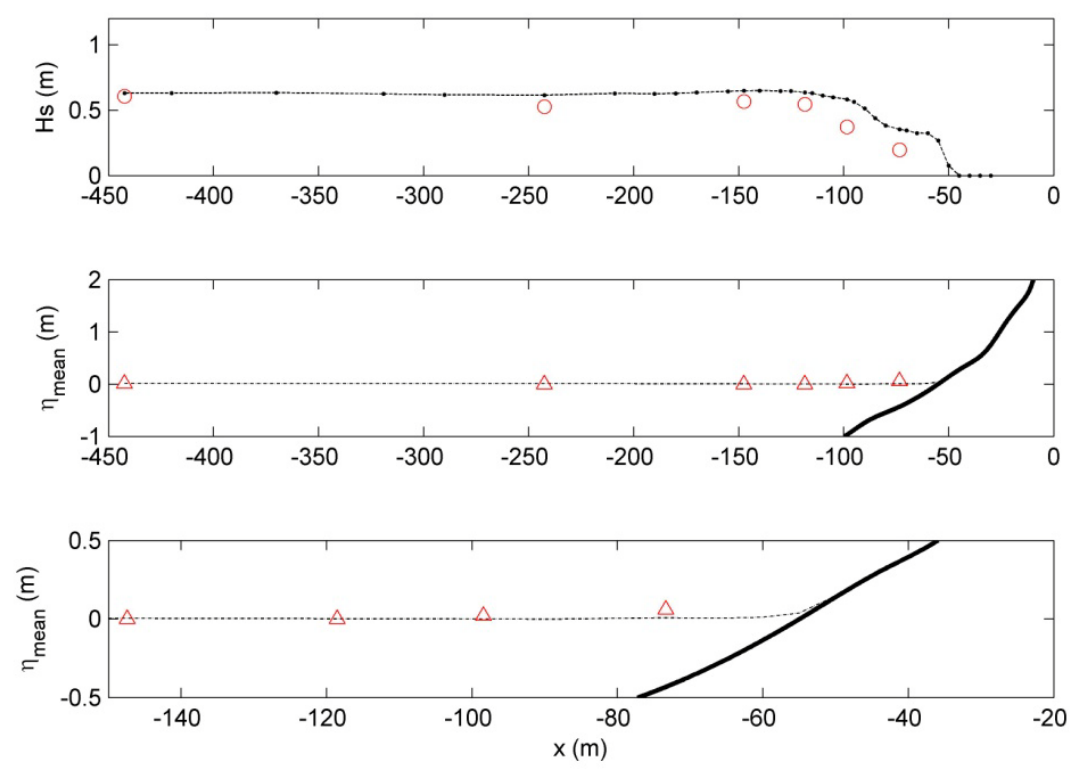

Figure 7 Cross-shore variations of wave heights (top) and setup (lower two panels) in Case 3.
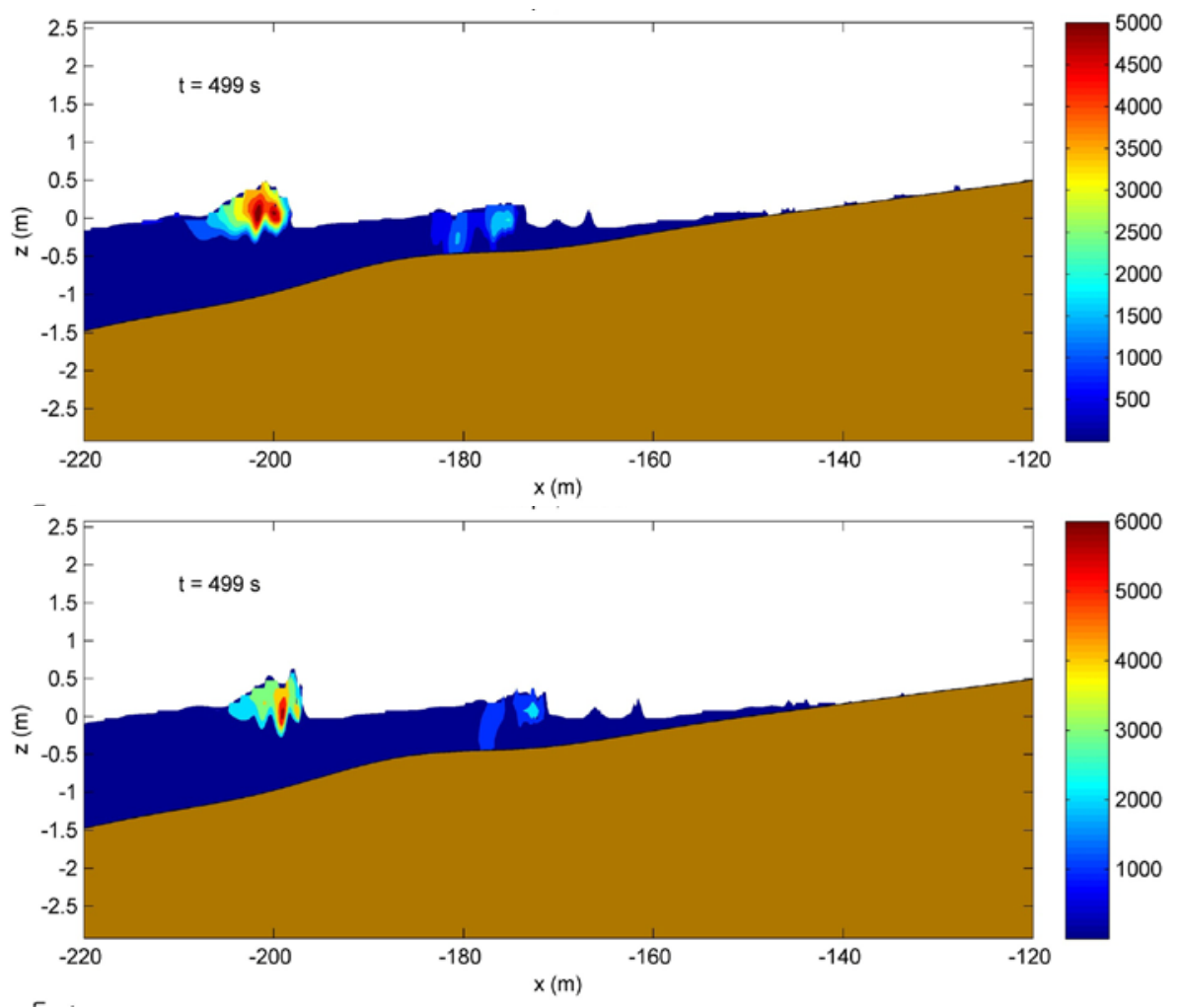

\section{CONCLUSIONS and DISCUSSIONS}

Field observation was conducted in macro-tidal sandy beaches of Korea. The data set included water surface elevation, waves, and currents and those were collected pressure type wave gages, ADV, and ADCP. Investigated wave transformations and wave setups in the inter-tidal zone on a macro-tidal sand beach with tide range of about $7 \mathrm{~m}$. Field data also showed that Transformations of wave heights over the inter-tidal zone was comparable to the measurements and wave setup was investigated to be influenced by tidal effect. 
RANS based numerical model (COBRAS) was used to try to predict tidal effect on the wave transformation, setup, and runup and to compare the results from field observation. Three different cases were selected; (1) waves only, (2) waves with ebb tide, and (3) waves with flood tide. Tin all three cases, COBRAS predicted well in terms of the cross-shore variation of the wave heights and setup.

However, COBRAS could not be applied for strong tide cases because the data points of field observation were not enough to be compared with numerical result during the period of strong tide. Therefore, COBRAS has obtained preliminary results with $0.1 \mathrm{~m} / \mathrm{s}$ of flood tide. The preliminary results showed that wave breaking pattern and runup appeared different when waves came with strong tidal current. Therefore, more study about wave-tide interaction in terms of wave transformation, setup, and runup.

In order to do that, authors are conducting two-dimensional laboratory experiment generating both waves and currents (ebb and flood). The results will be compared with COBRAS results.

\section{ACKNOWLEDGMENTS}

This work was supported by the KORDI (Grant PE98572, PE98573 and PM56300). This work was also supported by the Regional Innovation Center Program at Kwandong University of the Ministry of Knowledge Economy and a Manpower Development Program for Marine Energy by the Ministry of Land, Transport and Maritime Affairs (MLTM).

\section{REFERENCES}

Lee, H.J.; Chu, Y.S., and Park, Y.A., 1999. Sedimentary processes of fine-grained material and the effect of seawall construction in the Daeho macrotidal flat-nearshore area, northern west coast of Korea. Marine Geology, 157, 171-184.

Torres-Freyermuth, A.; Losada, I.J.; and Lara, J.L., 2007. Modeling of surf zone processes on a natural beach using Reynolds-Averaged Navier-Stokes equations, Journal of Geophysical Research, 112.

Wright, L.D.; Nielsen, P.; Short, A.D., and Green, M.O., 1982. Morphodynamics of a macrotidal beach. Marine Geology, 50, 97-128. 